\title{
A PHYSIOTHERAPIST'S COMMENTS ON SPORTS MEDICINE SERVICES
}

\author{
MARGARET JOHN, M.C.S.P., S.R.P. \\ Chairman of the Organisation of Physiotherapists in Private Practice
}

Austry House, 19 Station Road, Studley, Warwickshire

Sport for all is a stimulating phrase. We see it everywhere - on stickers in cars, on posters and even a franking on our mail. But what are the full implications of that statement. The more people that are involved in sport, the more the risk of injuries, therefore the need for more care and treatment of those injuries by those who are interested and qualified to treat them. "Who are these interested and qualified people!" - Some are physiotherapists.

In 1973 the Association of Chartered Physiotherapists in Sports Medicine was formed as a Specific Interest group of the Chartered Society of Physiotherapy. Its members are all chartered physiotherapists, and come from the National Health Service, the Armed Forces, Industrial and Private Practice. Its aims are to:

i) Improve the techniques and facilities for the prevention and treatment of sports injuries.

ii) Inform all interested bodies of its existence, and of the availability of such specialised service.

The A.C.P.S.M. elects a National Committee of Honorary Officers and area representatives who are responsible for organising their areas. The organisation has forged links of friendship and co-operations with B.A.S.M. and C.C.P.R. to the benefit of all the members and to the sportsmen they all meet.

There is an annual congress and many regional seminars and training sessions have been organised to which members, doctors, orthopaedic surgeons, traumatologists, physiologists, physical educationists, coaches, trainers and sports personnel meet to share information and increase their knowledge of conditions likely to require treatment and the methods of giving it.

The A.C.P.S.M. has contacted all the governing bodies and major sports organisations in the country to ask what treatment facilities are available, and offer help if required. Members and encouraged to contact local sports clubs and make it known that they are willing to treat sports injuries.

The A.C.P.S.M. has produced a directory of members and this has been distributed to as many sporting organisations and other interested bodies as possible. National Health Service Physiotherapy Departments who have General Practitioner Clinics, very often run small sports clinics in their own time, whereas other hospitals have sports clinics run in co-operation with interested consultants. Private practitioners have their own treatment rooms and clinics, and many members work as team physiotherapists, either full or part-time.

There are some Sports Medicine Centres in the Country, where enthusiastic teams of doctors, surgeons and physiotherapists are working hard together to maintain the fitness of our professional and national and international amateur sports teams; but even so the service is not adequate and many teams in many sports do not have either medical or physiotherapy support. But if there is an inadequate service for the top sportsmen and women - what then of the average - the mediocre - the Saturday and Sunday sportspeople. Rarely do they have their own medical officer on the touchline or trackside. Not many have their own physiotherapist, nor even a member of the team trained in first aid. When available members of the Red Cross, and St. John's Ambulance, do a good job, but injured players need more positive help. Where clubs have their own physiotherapist and medical advisers, they are fortunate. These are usually professional teams with high financial backing; the amateur teams, even at National level cannot always afford to pay for treatment for their players. So these evergrowing groups of friendly amateurs are those whose injured players add to the congestion of overworked casualty departments at weekends and G.P. clinics on Mondays. Often the injury is wrapped in a firm supporting bandage, and the player instructed "to rest", and come back in two weeks. Rest, as we know is admirable advice - but what does it mean? Go to bed and do nothing or - just do a bit less than ones normal daily programme. To an athlete who covers 20 miles a day, it might imply halving his schedule. To an amateur footballer, he may miss a couple of matches, but still have to go to work and stand around for $\mathbf{8}$ hours a day at a factory bench. It is this group of amateur sportsment who need most advice on the prevention of injury.

Every medical officer, physiotherapist and physical education specialist, pleads the need for adequate warm-up and warmdown and the wearing of correct sports attire, and general health care. But we are not yet getting through to all 
amateurs, (and some professional sportspeople), the essential need for a simple programme of injury prevention. Many do not even know the value of the I.C.E. routine - Ice, Compression and Elevation, immediately following injury.

To some, training is an unnecessary waste of time, and too often the attitude towards injury is "leave it alone and it will go away".

Some injuries are self-limiting, others cause great distress, when after a few weeks seemingly simple acute injuries become chronic from lack of easy basic care and advice.

Whether the work with sportsmen is on a small scale or at a sophisticated sports complex, there is a vital need for co-operation and co-ordination of services by medical teams, managers, coaches and trainers. Physiotherapists are often the vital link, and their frequent contact with players and coaches, enables them to detect faults in technique that may mar performance, and cause overuse and stress injuries. Whether they give simple first aid or other necessary treatment their help is invaluable.

Sport for all will be an impossible dream if the back-up service of adequate medical care cannot become a reality; lack of funds to finance this service is a constant headache. But with A.C.P.S.M. there is a growing organisation of enthusiastic physiotherapists willing to play their part in keeping Britain's sportsmen and women at play.

Whether the work with sportsmen is on a small scale or at a sophisticated sports complex, there is a vital need for co-operation and co-ordination of services by medical teams, managers, coaches and trainers. Physiotherapists are often the vital link, and their frequent contact with players and coaches, enables them to detect faults in technique that may mar performance, and cause overuse and stress injuries, which are often missed or not considered by doctors in general practice, or casualty officers.

Now that the Rules of Professional Conduct have become more liberal and state: "No Physiotherapist should treat a patient unless that patient has been referred to him/her by a Registered Medical or Dental Practitioner, except in an emergency or for some other exceptional reason or unless he/she has direct access to the patient's Doctor. It is obviou\& therefore that there is no reason why injured sportsmen should only receive First Aid treatment from any qualified physiotherapist, but treatment until recovery and full rehabilitation has taken place, as long as the telephone number af the patient's Doctor is known.

Naturally a physiotherapist would contact either Doctor or Hospital if there was the slightest doubt about the sportsman's condition. But there are so many injuries that can benefit from a course of treatment without referral to a doctor. If the physiotherapist has a good relationship with her local doctors, treatment of Sportsmen should be considered a valuable and time saving service, and not incur animosity or resentment by the doctors.

Exact prescription of treatment by a doctor is rarely necessary, the experienced physiotherapist will know which treatments are of most value and where sportsmen are concerned it is speed of recovery that matters and not a stereo-typed course of treatment.

When doctors and physiotherapists accept each other as mutual members of the Sportsmedicine team - sportsmen will get better treatment and we will all have greater respect for our individual specialities.

Sport for all will be an impossible dream if the back-up service of adequate sportsmedicine care cannot become a reality, lack of funds to finance this service is a constant headache. But with A.C.P.S.M. there is a growing organisation of enthusiastic physiotherapists willing to play their part in keeping Britains sportsmen and women at play. Whether they give simple first aid or other necessary treatment their help is invaluable. 